\title{
Al-TiC Composites Fabricated by a Thermally Activated Reaction Process in an Al Melt Using Al-Ti-C-CuO Powder Mixtures. Part I: Microstructural Evolution and Reaction Mechanism
}

\author{
YOUNG-HEE CHO, JUNG-MOO LEE, and SU-HYEON KIM
}

\begin{abstract}
Al matrix composites reinforced with $\mathrm{TiC}$ particles are fabricated by a thermally activated reaction of Al-Ti-C powder mixtures in an $\mathrm{Al}$ melt. In the presence of $\mathrm{CuO}$, reactant mixtures in the form of a pellet added to molten $\mathrm{Al}$ at temperatures higher than $1093 \mathrm{~K}\left(820{ }^{\circ} \mathrm{C}\right)$ instantly reach the peak temperature over $1785 \mathrm{~K}\left(1512^{\circ} \mathrm{C}\right)$, followed by combustion wave propagation with in situ synthesizing $\mathrm{TiC}$ with a size of approximately $1 \mu \mathrm{m}$. Incomplete reaction products such as unreacted $\mathrm{C}, \mathrm{Al}_{3} \mathrm{Ti}$, and $\mathrm{TiC}$ aggregates are also observed. The pellet microstructure evolution upon the combustion reaction indicates that preheating temperature, i.e., the initial melt temperature, affects both the thermodynamic and kinetic characteristics of the reaction, and thereby influences the final microstructure of the $\mathrm{Al} / \mathrm{TiC}$ composites. Based on the experimental and theoretical results, a sequence of the reaction leading upto the in situ synthesis of $\mathrm{TiC}$ is illustrated and the corresponding mechanism for the present process is proposed.
\end{abstract}

DOI: $10.1007 / \mathrm{s} 11661-014-2476-\mathrm{x}$

(C) The Minerals, Metals \& Materials Society and ASM International 2014

\section{INTRODUCTION}

Al-BASED metal matrix composites reinforced with TiC particulates have been extensively studied due to their high hardness and elastic modulus, low density, and good wettability with molten aluminum with low chemical reactivity. ${ }^{[1-6]} \mathrm{TiC}$ can be introduced to the $\mathrm{Al}$ matrix either by adding $\mathrm{TiC}$ powders directly into the melt, i.e., ex situ process, or by an in situ reaction between elemental powders of $\mathrm{Ti}$ and $\mathrm{C}$ sources. In the ex situ process, infiltrated reinforcing $\mathrm{TiC}$ particles react with the Al matrix at high temperature and form a deteriorating interface layer on them and have poor wettability with the matrix due to surface contamination of the reinforcements. In situ $\mathrm{TiC}$, on the other hand, is a thermodynamically stable phase formed by a chemical reaction and exhibits a contamination free interface with the Al matrix..$^{[4,7-11]}$ Among various in situ fabrication techniques suggested upto now, the self-propagating high temperature synthesis (SHS) developed by Merzhanov $^{[12]}$ is one of the most feasible and productive methods and involves ignition and self-sustaining combustion of reactants, which results in product formation.

Earlier studies adopted halide salts such as $\mathrm{Na}_{3} \mathrm{AlF}_{6},{ }^{[13,14]} \mathrm{K}_{x} \mathrm{AlF}_{6},{ }^{13,14]}$ and $\mathrm{K}_{2} \mathrm{TiF}_{6},{ }^{[15-17]}$ that were added to molten $\mathrm{Al}$ to prepare Al-Ti-C grain refiners. The use of those flux agents significantly

YOUNG-HEE CHO, Senior Researcher, and JUNG-MOO LEE and SU-HYEON KIM, Principal Researchers, are with the Division of Light Metals, Korea Institute of Materials Science, 797 Changwondaero, Changwon 642-831, South Korea. Contact e-mail: jmoolee@ kims.re.kr

Manuscript submitted April 7, 2014

Article published online August 14, 2014 increases the SHS reactivity, and thereby yields far more TiC in situ synthesized. ${ }^{[13,14]}$ Moreover, it has been proposed that the fluxes addition leads to a dramatic reduction in the delay time to the SHS reaction and increases the melt over-heating temperature. ${ }^{[13,14]} \mathrm{K}-\mathrm{Al}-\mathrm{F}$ salts generated by the reduction of $\mathrm{K}_{2} \mathrm{TiF}_{6}$, in particular, were suggested to clean the particle surface and to remove the oxide layer from the surface of the melt, which improves the wetting of the graphite particles, promoting the formation of $\mathrm{TiC} .^{[17-19]}$

Besides shortening the SHS reaction time, lowering the temperature that initiates a combustion reaction is of importance in a low energy and cost saving in situ process. Our recent study reported a very practical process of SHS combined with a conventional casting to fabricate in situ $\mathrm{Al} / \mathrm{TiC}$ composites. ${ }^{[20,21]}$ It is noted that a certain amount of $\mathrm{CuO}$ addition thermally activates a combustion reaction of the Al-Ti-C system, and thereby enables the formation of in situ $\mathrm{TiC}$ with a large volume fraction in an $\mathrm{Al}$ melt at a reasonably low temperature range of $1023 \mathrm{~K}$ to $1193 \mathrm{~K}\left(750{ }^{\circ} \mathrm{C}\right.$ to $\left.920{ }^{\circ} \mathrm{C}\right)$. The microstructure evolution during SHS of Al-Ti-C, however, has not been yet clearly understood, while several mechanisms of reaction synthesis of $\mathrm{TiC}$ for various processes have been suggested in the literature..$^{[7,22-29]}$ Tong and Fang ${ }^{[24]}$ employed a conventional melting process with rapid solidification for producing $\mathrm{Al} / \mathrm{TiC}$ composites and reported that $\mathrm{TiC}$ particles are in situ synthesized via the following reactions:

$$
\begin{gathered}
{[\mathrm{Ti}]+[\mathrm{C}]=\operatorname{TiC}(\mathrm{s})} \\
{[\mathrm{Ti}]+\mathrm{C}(\mathrm{s})=\operatorname{TiC}(\mathrm{s}),}
\end{gathered}
$$


where [Ti] and $[\mathrm{C}]$ are dilute solutes in liquid Al solution. Equation [1] has been proposed as dissolutionprecipitation mechanism wherein either $\mathrm{C}^{[23]}$ or $\mathrm{Ti}^{[25]}$ solute in an Al melt migrates toward its opponent element particles with a relatively larger particle size, followed by precipitation of TiC during SHS of an Al-Ti$\mathrm{C}$ powder mixture. Equation [2], on the other hand, is a solid-liquid reaction that involves the diffusion of $\mathrm{Ti}$ solutes in the $\mathrm{Al}$ melt toward a $\mathrm{C}$ solid phase across the solid-liquid reaction interface layer. A systematic study on the reaction mechanism based on both thermodynamics and differential thermal analysis ${ }^{[7]}$ has confirmed the presence of $\mathrm{Al}_{4} \mathrm{C}_{3}$ and suggested that, along with Eqs. [1] and [2], indirect reactions are also likely to occur to synthesize $\mathrm{TiC}$ during heating of an $\mathrm{Al}-\mathrm{Ti}-\mathrm{C}$ preform infiltrated with molten $\mathrm{Al}$ as follows:

$$
\begin{aligned}
3 \mathrm{Al}_{3} \mathrm{Ti}(\mathrm{s})+\mathrm{Al}_{4} \mathrm{C}_{3}(\mathrm{~s}) & =3 \mathrm{TiC}(\mathrm{s})+13 \mathrm{Al}(\mathrm{l}) \\
\mathrm{Al}_{3} \mathrm{Ti}(\mathrm{s})+\mathrm{C}(\mathrm{s}) & =\mathrm{TiC}(\mathrm{s})+3 \mathrm{Al}(\mathrm{l})
\end{aligned}
$$

Equation (3) is further supported by Kennedy et al. ${ }^{[26]}$ who suggested that $\mathrm{TiC}$ formation is associated with the reaction between $\mathrm{Al}_{4} \mathrm{C}_{3}$ and $\mathrm{Al}_{3} \mathrm{Ti}$ with the evidence of differential scanning calorimetry and X-ray diffraction traces. In the study, ${ }^{[26]}$ it was confirmed that $\mathrm{TiC}$ remains stable at temperatures above $1163 \mathrm{~K}$ $\left(890{ }^{\circ} \mathrm{C}\right)$ where $\mathrm{Ti}$ dissolved in liquid $\mathrm{Al}$ starts to react with $\mathrm{Al}_{4} \mathrm{C}_{3}$ through the $\mathrm{Al}_{3} \mathrm{Ti}$ dissolution as follows:

$$
\mathrm{Al}_{4} \mathrm{C}_{3}(\mathrm{~s})+3[\mathrm{Ti}]=3 \mathrm{TiC}(\mathrm{s})+13 \mathrm{Al}(\mathrm{l})
$$

More recently Ding et al. ${ }^{[27]}$ suggested the distribution and morphologies of TiC in Al-Ti-C master alloys are influenced by the synthesis temperature. When using a melt reaction process as reported in the study, ${ }^{[27]} \mathrm{TiC}$ aggregation is more likely to form by Eq. [5] at a melt temperature range of $1173 \mathrm{~K}$ to $1273 \mathrm{~K}\left(900{ }^{\circ} \mathrm{C}\right.$ to $1000{ }^{\circ} \mathrm{C}$ ), while $\mathrm{TiC}$ particles highly dispersed in the $\mathrm{Al}$ matrix are synthesized by Eq. [2] at $1523 \mathrm{~K}$ to $1573 \mathrm{~K}$ $\left(1250{ }^{\circ} \mathrm{C}\right.$ to $\left.1300{ }^{\circ} \mathrm{C}\right)$.

Besides the difference in the process methods and conditions, the difference in the reaction mechanisms of $\mathrm{TiC}$ synthesis may arise from various initial particle sizes and powder types of an Al-Ti-C system. In this study, we aim to clarify the responsible mechanism for the in situ synthesis of TiC based on a systematic investigation of the microstructural evolution of an Al-Ti-C pellet mixture during the combustion reaction process recently developed. More importantly, this may suggest a key clue to minimise such undesirable features as particle agglomeration and incomplete reaction products, and thereby enables the control of the microstructure of in situ $\mathrm{Al} / \mathrm{TiC}$ composites fabricated by the developed process.

\section{EXPERIMENTAL}

$\mathrm{Al} / \mathrm{TiC}$ composites were prepared by adding elemental powder mixture pellets into an $\mathrm{Al}$ melt with a size of $400 \mathrm{~g}$ placed at a temperature range of $1023 \mathrm{~K}$ to $1193 \mathrm{~K}\left(750{ }^{\circ} \mathrm{C}\right.$ to $\left.920{ }^{\circ} \mathrm{C}\right)$, followed by SHS reaction. In order to make a pellet, $\mathrm{Al}(99.5 \mathrm{pct}, \sim 30 \mu \mathrm{m}), \mathrm{Ti}$
(99.5 pct, $\sim 25 \mu \mathrm{m})$, graphite (99.999 pct, $\sim 95 \mu \mathrm{m})$, and $\mathrm{CuO}(99.95 \mathrm{pct}, \sim 8 \mu \mathrm{m})$ powders weighing a total of $40 \mathrm{~g}$ were mixed thoroughly at a ratio corresponding to that of stoichiometric $\mathrm{TiC}$ with excess $\mathrm{Al}$ of $1.5 \mathrm{~mol}$ and $0.1 \mathrm{~mol} \mathrm{CuO}$. The powder mixture was pressed into pellets in a 25 -mm-diameter die under a pressure of $130 \mathrm{MPa}$, and then the pellets were placed in a preheating furnace at $473 \mathrm{~K}\left(200{ }^{\circ} \mathrm{C}\right)$ for a complete dry before adding them to an $\mathrm{Al}$ melt.

The powder particle size and its distribution were analyzed by a laser diffraction method. The contents of the each powder were determined by considering the molar ratio of $\mathrm{Ti}$ and $\mathrm{C}$ as to form $1 \mathrm{~mol}$ of $\mathrm{TiC}$, as well as the volume fraction of the reinforcements. After a complete reaction, the melt was stirred for 10 minutes by rotating an impeller at $350-400 \mathrm{rpm}$ so as to disperse the reaction products uniformly in it and then cast into a preheated mold. For the microstructure analysis by an optical microscopy (OM) and a scanning electron microscopy (SEM) equipped with an energy-dispersive spectrometer (EDS) samples were sectioned and prepared by standard polishing procedures with a final polishing by a $0.05 \mu \mathrm{m}$ colloidal silica suspension. In situ-synthesized $\mathrm{TiC}$ particles of approximately $1 \mu \mathrm{m}$ size were further analyzed by a transmission electron microscopy. Thin foil specimens for the TEM analysis were prepared by twin-jet electropolishing in a solution of 25 pet nitric acid and 75 pct methanol. Additionally, in order to further inspect the macro/microstructures of pellets, some Al-Ti-C pellets plunged in molten aluminum at the various temperatures were taken out soon after the combustion reaction. Then the pellets were vertically cross-sectioned and prepared for metallography by the procedures described as above. The size and the volume fraction of the particles were quantitatively analyzed using an image analyzer (I-solution DT).

\section{RESULTS}

Figure 1 shows a typical microstructure of an $\mathrm{Al} / \mathrm{TiC}$ composite fabricated by the combustion reaction of a powder mixture containing carbon powder with a mean particle size of $95 \mu \mathrm{m}$ in molten Al. Along with a large volume fraction of $\mathrm{TiC}$ particles (in dark gray), incomplete reaction products, such as carbon particles unreacted (in black), angular $\mathrm{Al}_{3} \mathrm{Ti}$ phases (in light gray), and $\mathrm{TiC}$ clusters, are also present in the composite. In situ $\mathrm{TiC}$ with sizes less than $1 \mu \mathrm{m}$ are well distributed throughout the $\mathrm{Al}$ matrix, while $\mathrm{TiC}$ aggregates are often found to surround unreacted carbon. The $\mathrm{TiC}$ agglomeration is further examined on a sample deep etched in a solution of $70 \mathrm{~mL}$ water and $30 \mathrm{~mL} \mathrm{NaOH}$ and is presented in the inset of Figure 1.

Figure 2 shows the cross sectional microstructures of Al-Ti-C pellets taken from an Al melt soon after the SHS. It is interesting to note that the outer layer remains unreacted with containing a large volume fraction of coarse carbon in black and Al-Ti compounds, the most probably $\mathrm{Al}_{3} \mathrm{Ti}$. Increase in the melt temperature from $1023 \mathrm{~K}$ to $1193 \mathrm{~K}\left(750{ }^{\circ} \mathrm{C}\right.$ to $\left.920{ }^{\circ} \mathrm{C}\right)$, however, yields a far less unreacted layer and no unreacted region is 
observed in the pellet processed at $1193 \mathrm{~K}\left(920^{\circ} \mathrm{C}\right)$ particularly. Instead, only reacting and reacted layers are observed in the pellet and exhibit honeycomb networks of reaction products dispersed in the infiltrated Al. This suggests that the pellet after the combustion reaction becomes extremely porous, and thus the $\mathrm{Al}$ melt is more likely to penetrate into it, which is possibly due to the theoretical volume contraction of approximately 23.5 pet by the formation of $\mathrm{TiC}$ from $\mathrm{Ti}$ and $\mathrm{C}$.

As evidenced in the pellet microstructures in Figure 2, there is a certain reaction sequence involved for the process, which was also confirmed by thermal analysis of both the pellet and melt using thermocouples types $\mathrm{C}$ and K, respectively. ${ }^{[20]}$ Figure 3 shows time-temperature plots of both an Al-Ti-C pellet and an Al melt during the combustion reaction process that consists of three different steps: (1) preheating; (2) reaction and infiltration; and (3) reaction stabilization. In the initial stage, the pellet added to the melt is preheated during the incubation time until its temperature reaches an onset point of ignition. In the intermediate stage, the combustion reaction instantly takes place with a steep increase in the pellet temperature, followed by the Al infiltration that occurs nearly simultaneously, i.e., after 2-3 seconds of SHS. As well as the volume contraction upon synthesizing $\mathrm{TiC}$, it has been suggested that improvement of the wettability of $\mathrm{TiC}$ particles with liquid $\mathrm{Al}$ by a significant increase in the temperature ${ }^{[30]}$ during SHS may lead to the spontaneous Al melt infiltration into the pellet. ${ }^{[31]}$ When the heat loss due to the $\mathrm{Al}$ infiltration exceeds the heat generation from the reaction front, however, the pellet temperature starts to

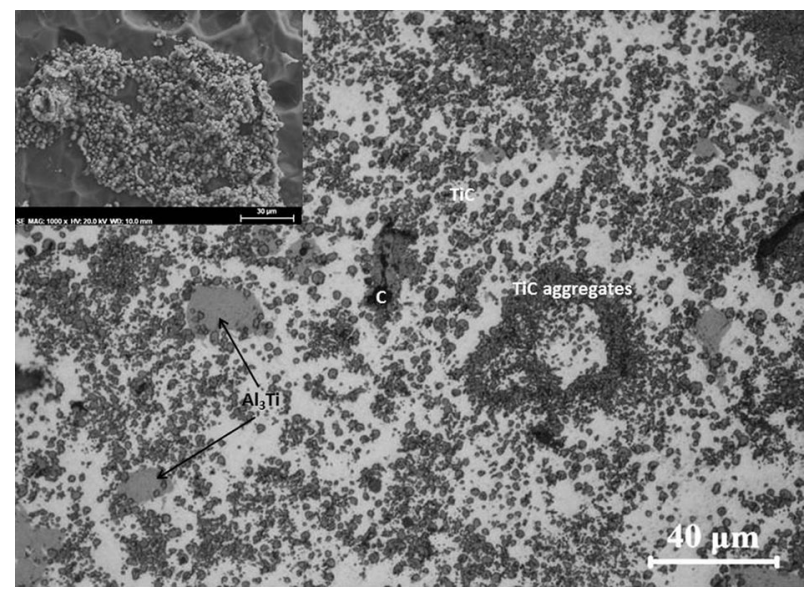

Fig. $1-\mathrm{OM}$ image showing a typical microstructure of $\mathrm{Al} / \mathrm{TiC}$ composites. TiC aggregates are further examined on a deep etched sample by SEM as shown in the inset.

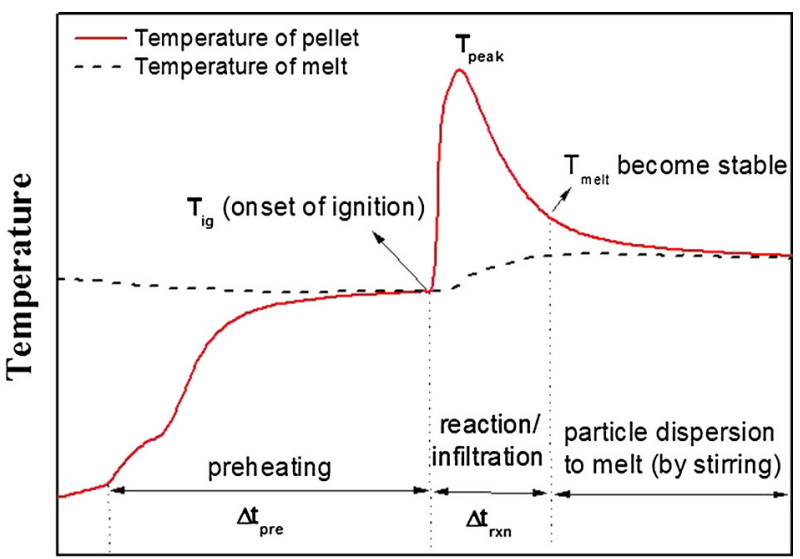

Time

Fig. 3-Time-temperature plots of a pellet and an $\mathrm{Al}$ melt during the process of reaction of Al-Ti-C powder mixture containing $\mathrm{CuO}$.
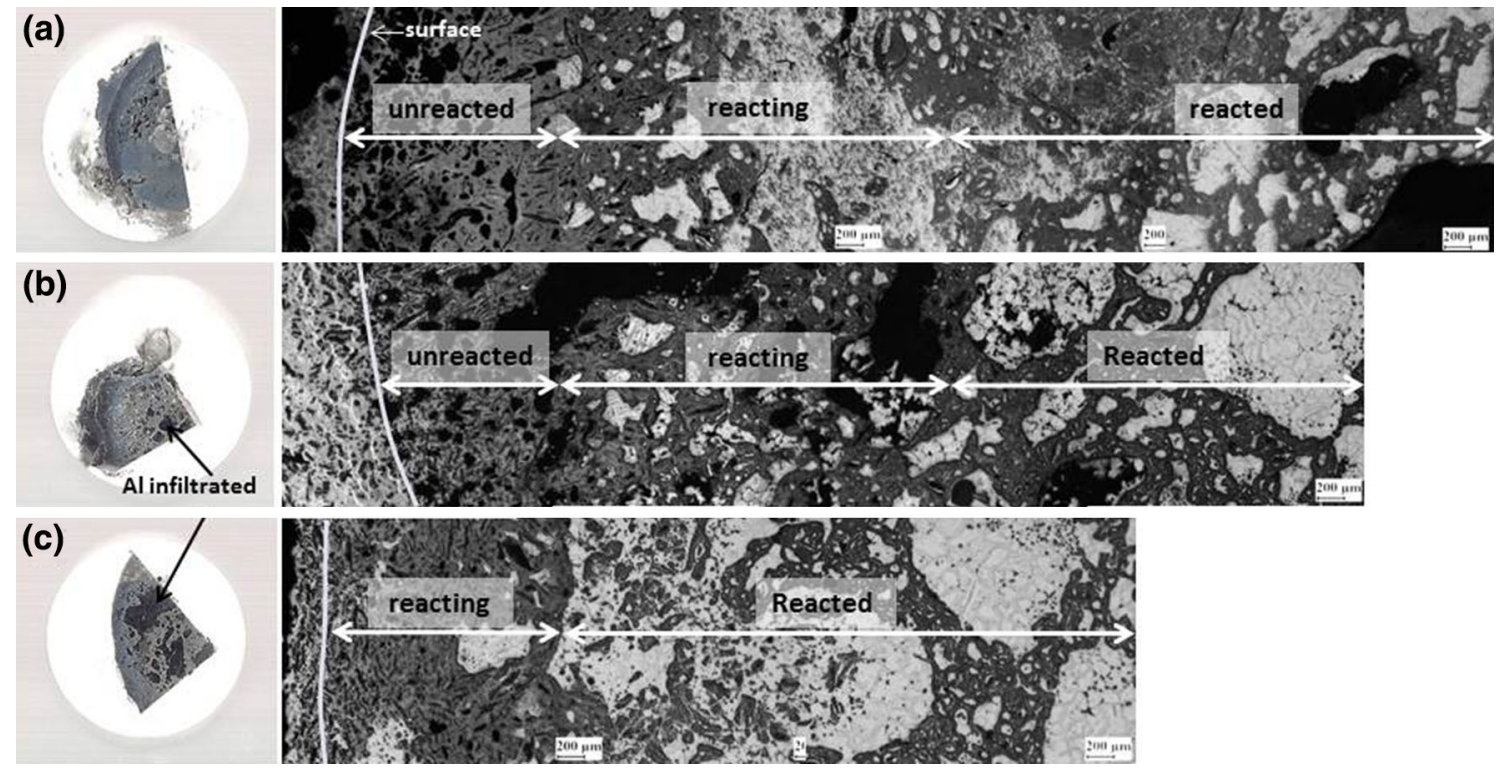

Fig. 2- OM images showing macro- and microstructures of cross-sectioned pellets plunged into an $\mathrm{Al}$ melt at different initial melt temperatures: (a) $1023 \mathrm{~K}\left(750^{\circ} \mathrm{C}\right)$; (b) $1093 \mathrm{~K}\left(820^{\circ} \mathrm{C}\right)$; and $(c) 1193 \mathrm{~K}\left(920^{\circ} \mathrm{C}\right)$. 
decrease, slowing down or halting the combustion wave propagation. In the final stage, the pellet temperature becomes equal to the melt temperature with the reaction stabilized and then reaction products in the pellet are readily dispersed into the $\mathrm{Al}$ melt by mechanical stirring. The thermal analysis results generated at each melt temperature are listed in Table I.

Looking further into the microstructures in each layer of the pellets, the unreacted region mainly consists of angular $\mathrm{Al}_{3} \mathrm{Ti}$ and unreacted $\mathrm{C}$ particles as shown in Figure 4, while a large volume fraction of $\mathrm{TiC}$ is present in the reacted region (see Figure 5). The formation of $\mathrm{Al}_{2} \mathrm{O}_{3}$ (in black) and $\mathrm{Al}_{2} \mathrm{Cu}$, which is associated with the decomposition of $\mathrm{CuO}$, is also found along with acicular $\mathrm{Al}_{3} \mathrm{Ti}$ phases (not presented in Figure 5) in the reacted region of the pellet as shown in Figure 5(b). In the reacting region as shown in Figure 6, TiC particles are either well dispersed in the Al infiltrated or present as aggregates which are often found adjacent to unreacted $\mathrm{C}$ particles. When moving toward the boundary between the unreacted and reacting layers, a large number of $\mathrm{TiC}$ aggregates are synthesized and the location is likely to coincide with that of angular $\mathrm{Al}_{3} \mathrm{Ti}$ as shown in Figure 7.

The final microstructures of $\mathrm{Al} / \mathrm{TiC}$ composites, which are named as melt microstructures, wherein the reaction products in the pellets are dispersed, were investigated in our earlier study. ${ }^{[20]}$ Similarly to the pellet microstructures, increase in the melt temperature from $1023 \mathrm{~K}$ to $1193 \mathrm{~K}\left(750{ }^{\circ} \mathrm{C}\right.$ to $\left.920{ }^{\circ} \mathrm{C}\right)$ significantly facilitates the in situ synthesis of TiC. Figures 8(a) and (b) show a TEM micrograph exhibiting an in situ-

Table I. The Thermal Analysis Results Generated at the Initial Melt Temperature of $1023 \mathrm{~K}, 1093 \mathrm{~K}$, and $1193 \mathrm{~K}$ $\left(750{ }^{\circ} \mathrm{C}, 820^{\circ} \mathrm{C}\right.$, and $\left.920^{\circ} \mathrm{C}\right)$

\begin{tabular}{lccccc}
\hline Melt Temp. $\left[\mathrm{K}\left({ }^{\circ} \mathrm{C}\right)\right]$ & $T_{\text {ig }}\left[\mathrm{K}\left({ }^{\circ} \mathrm{C}\right)\right]$ & $T_{\text {peak }}\left[\mathrm{K}\left({ }^{\circ} \mathrm{C}\right)\right]$ & $\Delta t_{\text {pre }}(\mathrm{s})$ & $\Delta t_{\text {rxn }}(\mathrm{s})$ & Remarks \\
\hline $1023(750)$ & $1040.8(767)$ & $1318.8(1045.8)$ & 54 & 17 & $T<1554 \mathrm{~K}\left(1281{ }^{\circ} \mathrm{C}\right)($ only Eq. [2]) \\
$1093(820)$ & $1050.5(777.5)$ & $1785.9(1512.9)$ & 29 & 14 & $T>1554 \mathrm{~K}\left(1281{ }^{\circ} \mathrm{C}\right)(\mathrm{Eqs} .[1],[2])$ \\
$1193(920)$ & $1093.2(820.2)$ & $2000(1727)$ & 10 & 12 & $T>1554 \mathrm{~K}\left(1281{ }^{\circ} \mathrm{C}\right)(\mathrm{Eqs} .[1],[2])$ \\
\hline
\end{tabular}

$T_{\text {ig: }}$ ignition temperature; $T_{\text {peak }}$ : peak temperature; $\Delta t_{\text {pre }}$ : preheating time; $\Delta t_{\text {rxn }}$ : reaction/infiltration time.
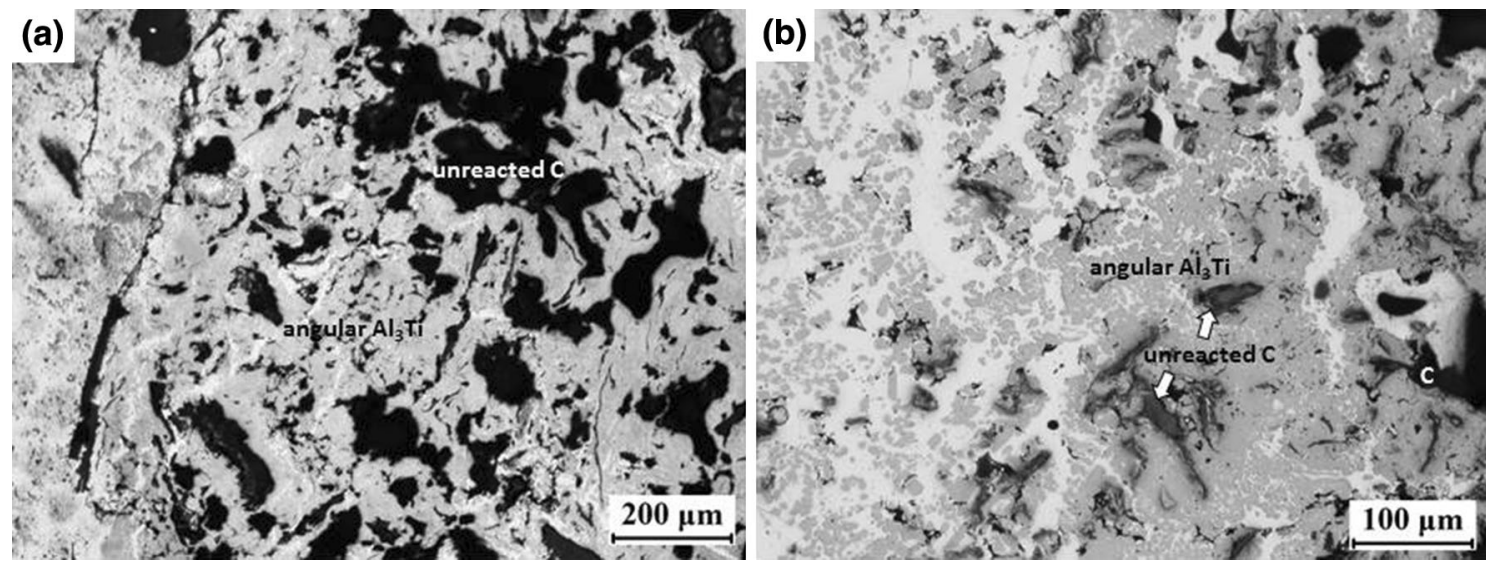

Fig. $4-\mathrm{OM}$ images showing the unreacted region of the pellet processed at $(a) 1023 \mathrm{~K}\left(750{ }^{\circ} \mathrm{C}\right)$ and $(b) 1093 \mathrm{~K}\left(820^{\circ} \mathrm{C}\right)$.
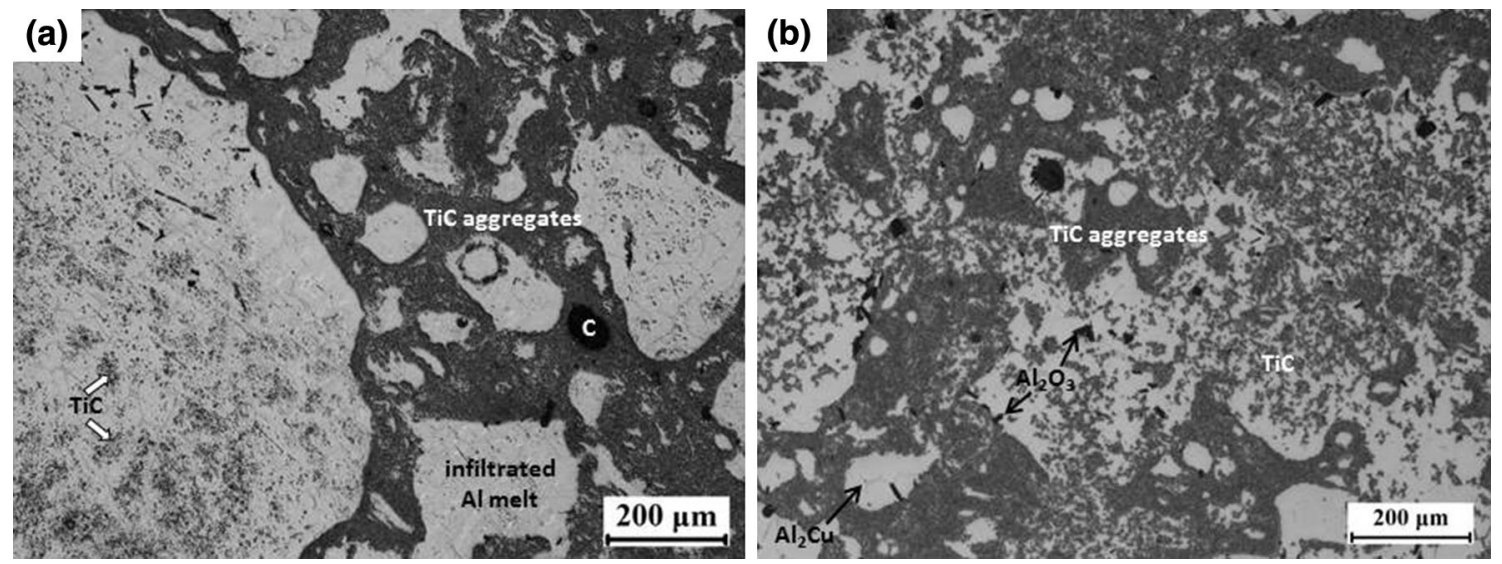

Fig. 5- OM images showing the reacted region of the pellet processed at $(a) 1023 \mathrm{~K}\left(750{ }^{\circ} \mathrm{C}\right)$ and $(b) 1093 \mathrm{~K}\left(820^{\circ} \mathrm{C}\right)$. 

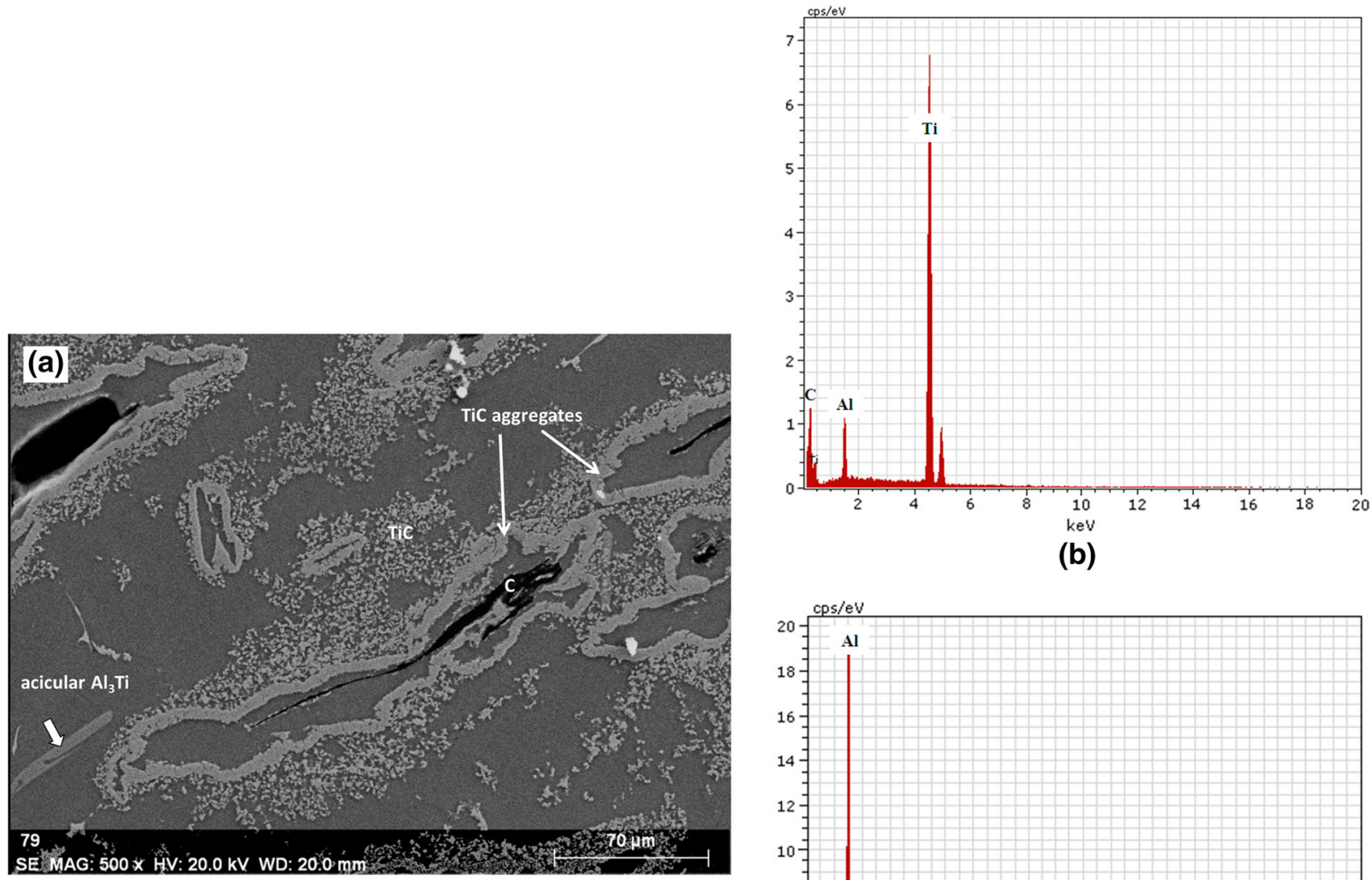

(b)

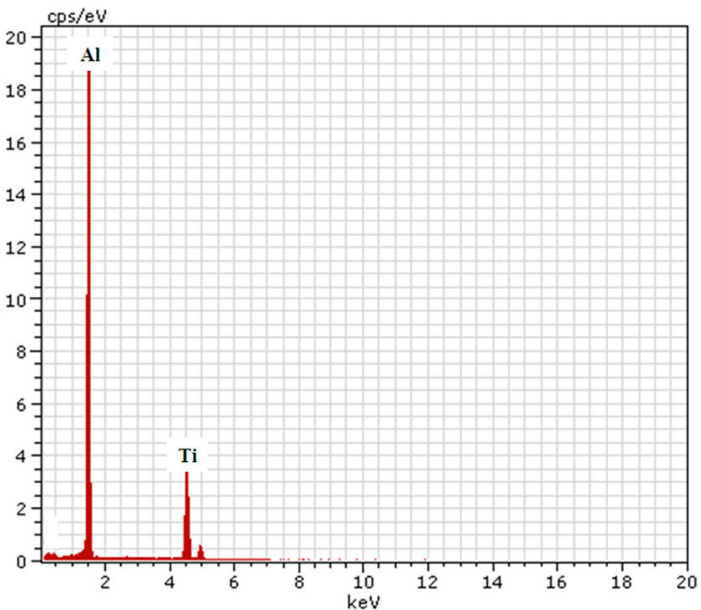

(c)

Fig. 6- (a) SEM image showing the reacting region of the pellet processed at $1093 \mathrm{~K}\left(820^{\circ} \mathrm{C}\right)$. EDS spectra obtained from $(b)$ TiC aggregates and (c) acicular $\mathrm{Al}_{3} \mathrm{Ti}$ phase.

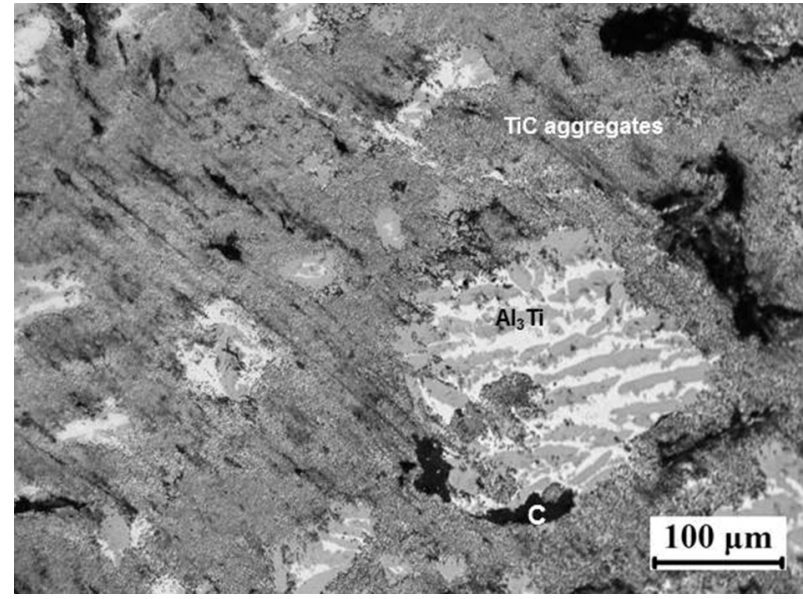

Fig. 7-OM image showing the boundary between the unreacted and reacting layers of the pellet processed at $1093 \mathrm{~K}\left(820^{\circ} \mathrm{C}\right)$. synthesized TiC (arrowed) and its corresponding EDS spectrum, respectively. The diffraction pattern obtained from the phase is also presented in the inset of Figure 8(a), which confirms that the phase is TiC (cubic, $F m \overline{3} m, a=0.431 \mathrm{~nm}$ ). It is also noted that acicular $\mathrm{Al}_{3} \mathrm{Ti}$ is the most likely to form at $1193 \mathrm{~K}\left(920^{\circ} \mathrm{C}\right)$ (see Eq. [7]). This is probably due to the fact that the melt temperature increase may provide more external heat input that may facilitate local melting of $\mathrm{Al}$ where $\mathrm{Ti}$ atoms get dissolved. ${ }^{[7,11,26,32]}$ For the comparison of microstructures in pellets and melts, both area fractions of each layer in the pellets and volume fractions of constituent phases in the melt are quantitatively analyzed and plotted as a function of the melt temperature in Figure 9. Increasing the melt temperature leads to an increase in the area fraction of the reacted layer in the pellet microstructure, whereas those of the unreacted and reacting layers are reduced as shown in Figure 9(a). 

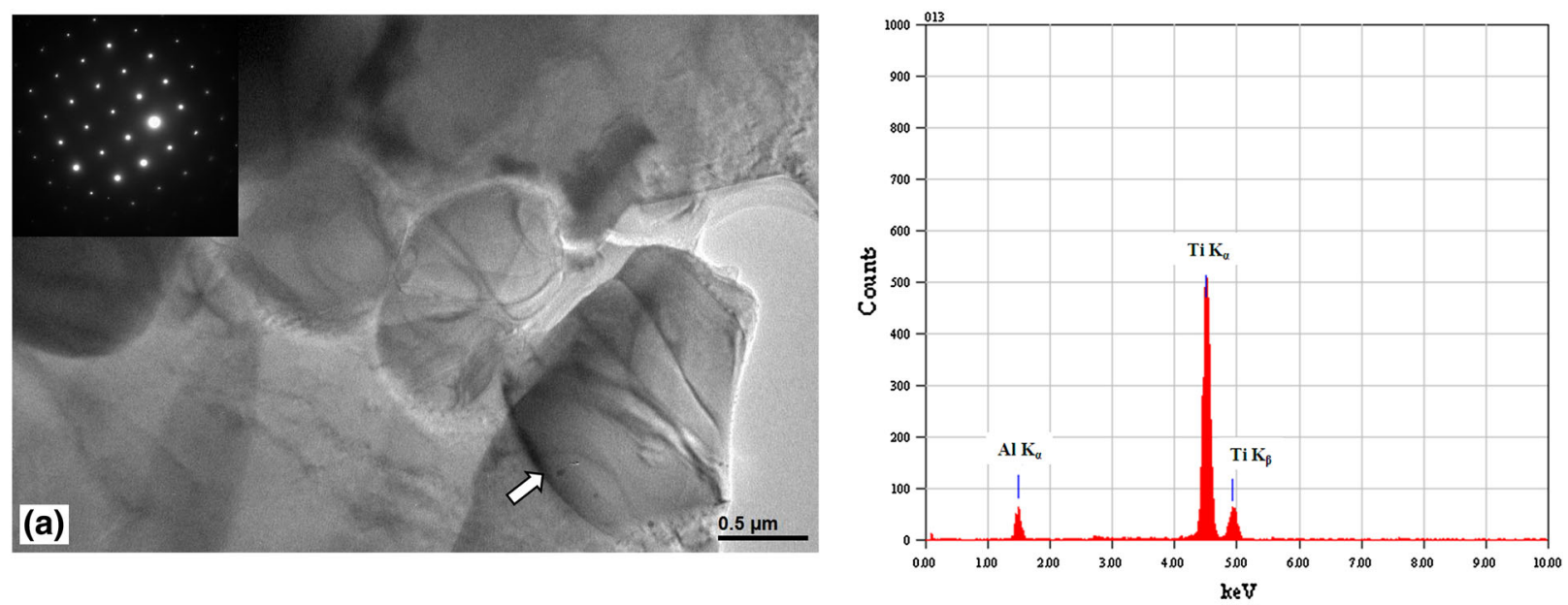

(b)

Fig. 8- (a) TEM micrograph showing in situ-synthesized TiC (arrowed) with its diffraction pattern presented in the inset and (b) EDS spectrum obtained from the TiC particle.

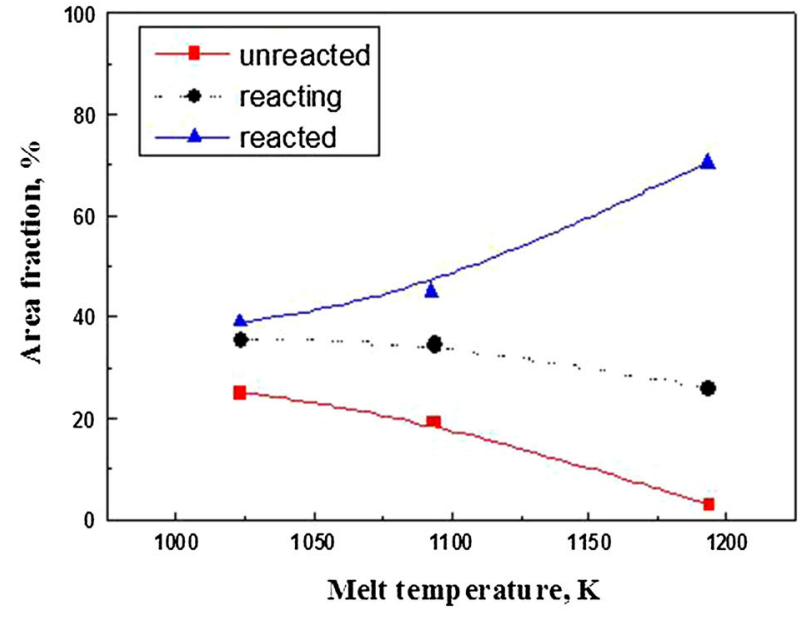

(a)

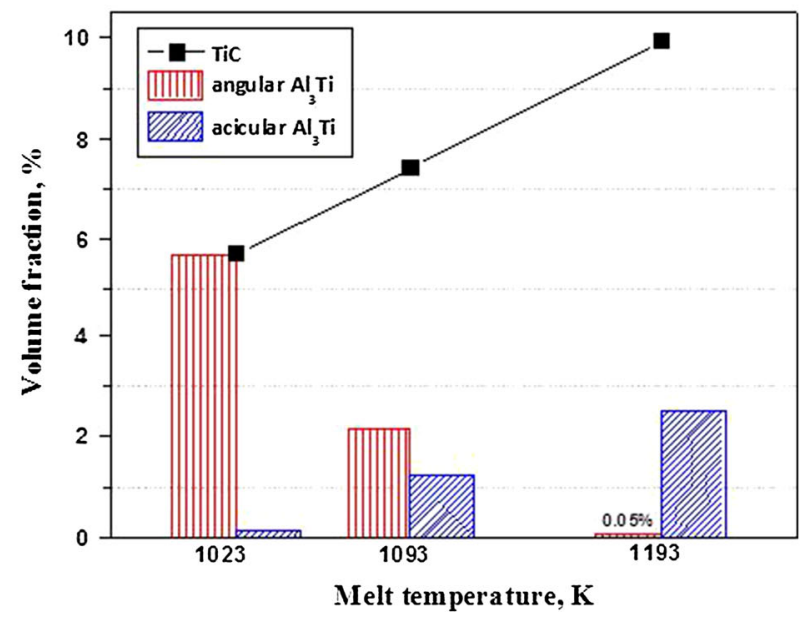

(b)

Fig. 9-(a) Area fraction of each layer in pellet microstructures and (b) volume fractions of constituent phases in melt microstructures plotted as a function of melt temperature.

This is in good agreement with the melt microstructures that exhibit a significant increase in the volume fractions of $\mathrm{TiC}$ and acicular $\mathrm{Al}_{3} \mathrm{Ti}$ with producing far less angular $\mathrm{Al}_{3} \mathrm{Ti}$, a major constituent phase in the unreacted layer of pellets when increasing the melt temperature (Figure 9(b)).

\section{DISCUSSION}

\section{A. Thermodynamics}

Combustion reaction of Al-Ti-C generally starts with ignition when the pellet mixture reaches a critical temperature by an external heat input, for instance, the melt temperature in the present work. Then serial chemical reactions occur to in situ synthesize TiC during the combustion wave propagation. Table II lists all the candidate reactions for the formation of $\mathrm{TiC}$ in the Al-Ti-C system, which all are proved to be thermodynamically stable in the processing conditions employed. ${ }^{[24,33]}$ In the initial stage of the combustion reaction, a preheating stage as defined in Figure 3, the pellet temperature remains still too low to initiate the combustion reaction. Hence, along with unreacted $\mathrm{C}$ particles, angular $\mathrm{Al}_{3} \mathrm{Ti}$ which are mainly present in the unreacted layer as evidenced in Figure 4, are formed by the reaction between solid $\mathrm{Al}$ and solid $\mathrm{Ti}$ as follows ${ }^{[7,11,26,32]}$.

$$
3 \mathrm{Al}(\mathrm{s})+\mathrm{Ti}(\mathrm{s})=\mathrm{Al}_{3} \mathrm{Ti}(\mathrm{s})
$$

As the reaction proceeds, the pellet temperature exceeds the melt temperature and sharply increases upto its peak temperature after reaching the onset point of 


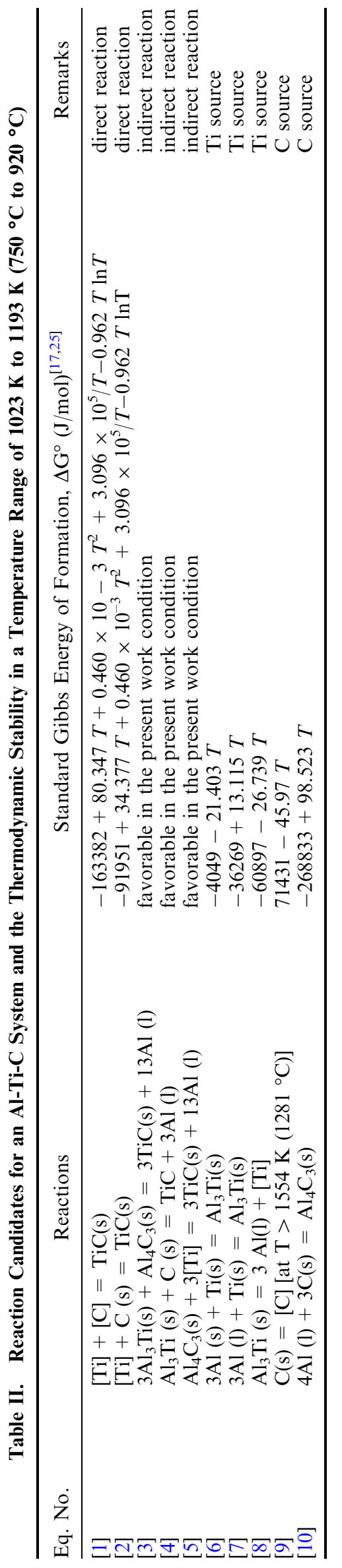

ignition. Table I shows the peak temperatures experimentally analyzed during the combustion reaction of AlTi-C pellets, which goes upto over $1300 \mathrm{~K}\left(1027^{\circ} \mathrm{C}\right)$. It is, therefore, suggested that $\mathrm{TiC}$ synthesis in the reacting and reacted layers are more likely to involve the direct reactions, i.e., Eqs [1] and [2], which is preceded by following reactions

$$
\begin{gathered}
3 \mathrm{Al}(\mathrm{l})+\mathrm{Ti}(\mathrm{s})=\mathrm{Al}_{3} \mathrm{Ti}(\mathrm{s}) \\
\mathrm{Al}_{3} \mathrm{Ti}(\mathrm{s})=3 \mathrm{Al}(\mathrm{l})+[\mathrm{Ti}] \\
\mathrm{C}(\mathrm{s})=[\mathrm{C}] \\
4 \mathrm{Al}(\mathrm{l})+3 \mathrm{C}(\mathrm{s})=\mathrm{Al}_{4} \mathrm{C}_{3}(\mathrm{~s})
\end{gathered}
$$

Considering the thermodynamic stability of $\mathrm{C}$ sources, Eq. [9], in particular, takes place forward at temperatures of over $1554 \mathrm{~K}\left(1281^{\circ} \mathrm{C}\right) .{ }^{[24]}$ This importantly suggests that Eq. [1] is thermodynamically preferable because $\mathrm{C}$ atoms can be present as dilute solutes dissolved in liquid $\mathrm{Al}$ at temperatures exceeding $1554 \mathrm{~K}$ $\left(1281{ }^{\circ} \mathrm{C}\right)$, whereas the liquid-solid reaction process, Eq. [2] is responsible for the $\mathrm{TiC}$ synthesis at a temperature lower than the critical temperature, i.e., $1554 \mathrm{~K}$ $\left(1281^{\circ} \mathrm{C}\right)$. TiC aggregates mainly present in the reacted layer of the pellet as evidenced in Figure 5(a) are, therefore, considered to be formed by Eq. [2] because of its relatively low peak temperature of $1319 \mathrm{~K}\left(1046^{\circ} \mathrm{C}\right)$ at a melt temperature of $1023 \mathrm{~K}\left(750^{\circ} \mathrm{C}\right)$. When increasing the melt temperature to $1093 \mathrm{~K}\left(820^{\circ} \mathrm{C}\right)$, $\mathrm{TiC}$ particles well dispersed in the $\mathrm{Al}$ matrix are observed in the reacted and the reacting layers of the pellet as shown in Figures 5(b) and 6(a), respectively, and are suggested to form by the dissolution-precipitation process, Eq. [1], as the peak temperature reaches approximately $1785 \mathrm{~K}\left(1512^{\circ} \mathrm{C}\right)$. Besides, evidence of $\mathrm{TiC}$ aggregates often found near unreacted $\mathrm{C}$ indicates that $\mathrm{TiC}$ formation is driven by the migration of $\mathrm{Ti}$ solutes in liquid $\mathrm{Al}$ toward the solid $\mathrm{C}$ when the temperature is lower than the $1554 \mathrm{~K}\left(1281^{\circ} \mathrm{C}\right.$ ) (see Figure 6(a)). At the boundary between the unreacted and reacting layers of the pellet as shown in Figure 7, however, colonies of $\mathrm{TiC}$ aggregates, which are often found to surround $\mathrm{Al}_{3} \mathrm{Ti}$ phases, suggest that the $\mathrm{TiC}$ formation occurs via a different reaction route, i.e., Eqs. [3] or [4] due to the temperature far below the peak temperature.

Now a question may arise regarding the presence of $\mathrm{Al}_{4} \mathrm{C}_{3}$, which has been reported to form prior to Eq. [3] that takes place at $1133 \mathrm{~K}$ to $1163 \mathrm{~K}\left(860{ }^{\circ} \mathrm{C}\right.$ to $\left.890{ }^{\circ} \mathrm{C}\right)^{[7,26]}$ but is rarely observed in this work. Theoretical thermodynamic calculation suggests that the formation of $\mathrm{Al}_{4} \mathrm{C}_{3}$ is more favorable than that of $\mathrm{TiC}$ below about $1500 \mathrm{~K}\left(1227{ }^{\circ} \mathrm{C}\right),{ }^{[34]}$ which is supplemented by Fine and Conley ${ }^{[35]}$ who reported that the formation of $\mathrm{TiC}$ is always stable throughout the temperature range of upto $2073 \mathrm{~K}\left(1800{ }^{\circ} \mathrm{C}\right)$, when considering the free energy of formation of both per mole of $\mathrm{C}$ basis. Those calculations are, however, based on $1 \mathrm{~mol}$ of pure solid 
C equilibrated with pure solid Ti and pure solid or liquid $\mathrm{Al}$ and have been further corrected by Rapp and Zheng ${ }^{[33]}$ who considered $\mathrm{C}$ (dissolved or solid), dissolved $\mathrm{Ti}$ and liquid Al. The calculated results predicted that $\mathrm{TiC}$ is thermodynamically more stable than $\mathrm{Al}_{4} \mathrm{C}_{3}$ in the temperature range of $1150 \mathrm{~K}$ to $1800 \mathrm{~K}\left(877^{\circ} \mathrm{C}\right.$ to $\left.1527{ }^{\circ} \mathrm{C}\right)$ except for a very low concentration of dissolved $\mathrm{Ti}$ $([\mathrm{Ti}]<0.5 \mathrm{wt} \mathrm{pct}) .{ }^{[33]}$ Microstructures in this study are nevertheless unlikely to confirm the direct evidence of the formation of $\mathrm{Al}_{4} \mathrm{C}_{3}$. This may suggest that Eq. [5], which involves the reaction between $\mathrm{Al}_{4} \mathrm{C}_{3}$ and [Ti], is very limited, and thus the standard Gibbs energy of $\mathrm{TiC}$ formation can be mainly driven by direct reactions between [Ti] and pure solid $\mathrm{C}$ or [C], i.e., Eqs. [1] and [2], respectively.

\section{B. Kinetics}

\section{The kinetics of $\mathrm{Al}_{3} \mathrm{Ti}$ formation}

Based on the experimental results of microstructures and thermodynamic analysis, $\mathrm{TiC}$ synthesis mainly occurs by both the dissolution-precipitation mechanism, Eq. [1], and the solid-liquid reaction process, Eq. [2]. From a kinetic view point, it is, therefore, of importance that the decomposition of $\mathrm{Al}_{3} \mathrm{Ti}$ into [Ti] and liquid $\mathrm{Al}$ via Eqs. [6] to [8] needs to proceed to get those major reactions operated. Assuming that the decomposition, Eq. [8], is much faster than the formation of $\mathrm{Al}_{3} \mathrm{Ti}$, Eq. [7] in particular, the overall reaction kinetics are governed by the $\mathrm{Al}_{3} \mathrm{Ti}$ formation of which the process has been proposed to have two steps by the spherical shell model ${ }^{[36-38]}$ as illustrated in Figure 10: (1) diffusion of $\mathrm{Al}$ to $\mathrm{Ti}$ through $\mathrm{Al}_{3} \mathrm{Ti}$ layer; and (2) reaction between $\mathrm{Al}$ and $\mathrm{Ti}$ at the $\mathrm{Al}_{3} \mathrm{Ti} / \mathrm{Ti}$ interface. The model defines a spherical Ti particle with an initial radius of $r_{o}$ that decreases to $r_{i}$ as Ti is consumed to form $\mathrm{Al}_{3} \mathrm{Ti}$. Then the diffusion velocity of $\mathrm{Al}$ in the $\mathrm{Al}_{3} \mathrm{Ti}$ layer, $V_{d}(\mathrm{~mol} / \mathrm{s})$ can be calculated using Eq. [11],

$$
V_{d}=4 \pi\left(\frac{D_{\mathrm{Al}}}{\gamma_{\mathrm{Al}}}\right)\left(\frac{\rho_{\mathrm{Al}_{3} \mathrm{Ti}}}{M_{\mathrm{Al}_{3} \mathrm{Ti}}}\right)\left(\frac{r_{o} r_{i}}{r_{0}-r_{i}}\right)\left(1-a_{\mathrm{Al}}\right)
$$

where $D_{\mathrm{Al}}$ is the diffusion coefficient of $\mathrm{Al}$ in $\mathrm{Al}_{3} \mathrm{Ti}$, $\gamma_{\mathrm{Al}}$ is the activity coefficient, $a_{\mathrm{Al}}$ is the activity of $\mathrm{Al}$ in

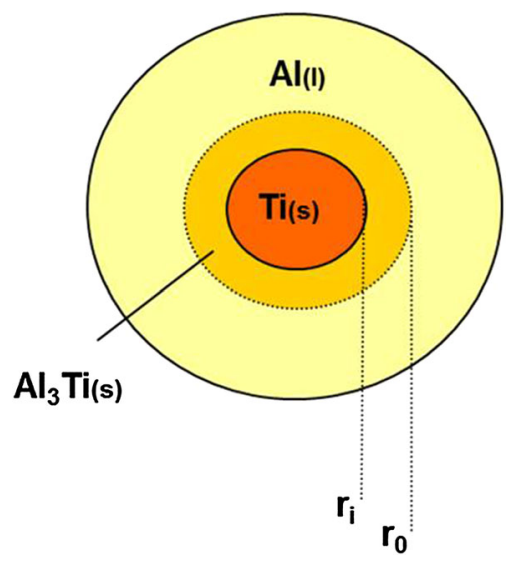

Fig. 10-A schematic diagram of the kinetic model of $\mathrm{Al}_{3} \mathrm{Ti}$ formation during the reaction of an Al-Ti-C mixture.
$\mathrm{Al}_{3} \mathrm{Ti}, \rho_{\mathrm{Al}_{3} \mathrm{Ti}}$, and $M_{\mathrm{Al}_{3} \mathrm{Ti}}$ are the density and molecular weight of $\mathrm{Al}_{3} \mathrm{Ti}$, respectively. When the reaction occurs following the $\mathrm{Al}$ diffusion, the reaction velocity, $V_{c}$ $(\mathrm{mol} / \mathrm{s})$ at the $\mathrm{Al}_{3} \mathrm{Ti} / \mathrm{Ti}$ interface is calculated by Eq. [12],

$$
V_{c}=\frac{4}{3} \pi r_{i}^{2}\left(K_{c} \cdot a_{\mathrm{Al}}-K_{b}\right),
$$

where $K_{c}$ and $K_{b}$ are, respectively, the rate constants of the forward and backward reactions of Eq. [7]. Based on the law of mass conservation, both rates of the diffusion and the reaction, $V_{d}$ and $V_{c}$, respectively, are equal to the overall reaction velocity, $V(\mathrm{~mol} / \mathrm{s})$, which is defined as,

$$
V=\frac{4 \pi r_{o}^{2}}{\frac{\gamma_{\mathrm{Al}} \cdot r_{o}\left(r_{o}-r_{i}\right)}{r_{i} \cdot D_{\mathrm{Al}}} \cdot\left(\frac{\rho_{\mathrm{Al}_{3} \mathrm{Ti}}}{M_{\mathrm{Al}} \mathrm{Ti}_{\mathrm{i}}}\right)+\frac{3 r_{o}^{2}}{r_{i}^{2} \cdot K_{c}}}
$$

$\mathrm{V}$ in Eq. [13] is also equal to the decrease rate of the Ti particle volume, $V_{r}$, which can be obtained by Eq. [14],

$$
\mathrm{V}_{r}=4 \pi r_{i}^{2} \frac{\rho_{\mathrm{Ti}}}{M_{\mathrm{Ti}}} \frac{d r_{i}}{d t}
$$

where $\rho_{\mathrm{Ti}}$ and $M_{\mathrm{Ti}}$ are the density and molecular weight of $\mathrm{Ti}$, respectively. Thus the time, $t$, for the complete reaction of solid $\mathrm{Ti}$ and liquid $\mathrm{Al}$ to from $\mathrm{Al}_{3}$ Ti can be given by

$$
\mathrm{t}=\left(\frac{\rho_{\mathrm{Ti}}}{M_{\mathrm{Ti}}}\right)\left(\frac{\gamma_{\mathrm{Al}} \cdot r_{o}^{2}}{6 D_{\mathrm{Al}}} \cdot \frac{M_{\mathrm{Al}_{3} \mathrm{Ti}}}{\rho_{\mathrm{Al}_{3} \mathrm{Ti}}}+\frac{3 r_{o}}{K_{c}}\right)
$$

Here, $\quad D_{\mathrm{Al}}=3.82 \times 10^{2} \exp (-293000 / R T)\left(\mathrm{m}^{2} / \mathrm{s}\right)$ and $\quad K_{c}=5.55 \times 10^{3} \exp (-125000 / R T)\left(\mathrm{mol} / \mathrm{m}^{2} \mathrm{~s}\right)^{[37]}$ are used in our calculations. Figure 9(a) shows the calculated reaction time of $\mathrm{Al}_{3} \mathrm{Ti}$ formation as a function of Ti particle size. Considering the thermal analysis results of the total reaction time, $\Delta t\left(\Delta t=\Delta t_{\mathrm{pre}}+\Delta t_{\mathrm{rxn}}\right)$, which are experimentally measured as 71,43 , and $22 \mathrm{~s}$ for the initial melt temperature of $1023 \mathrm{~K}, 1093 \mathrm{~K}$, and $1193 \mathrm{~K}\left(750^{\circ} \mathrm{C}, 820^{\circ} \mathrm{C}\right.$, and $920^{\circ} \mathrm{C}$ ), respectively, (see Table I), Figure 11(a) importantly predicts the maximum particle sizes of $\mathrm{Ti}$ for the complete reaction. At $1023 \mathrm{~K}\left(750^{\circ} \mathrm{C}\right)$, for instance, Ti particles with sizes less than $30 \mu \mathrm{m}$ as shown in Figure 11(a) can react to form $\mathrm{Al}_{3} \mathrm{Ti}$, and thus the Ti powders used in the present work may not be completely reacted to form $\mathrm{Al}_{3} \mathrm{Ti}$ due to the large mean particle size of $25 \mu \mathrm{m}$ (Figure 11(b)), which limits the $\mathrm{TiC}$ formation. However, in the melt microstructure, $\mathrm{Al}_{3} \mathrm{Ti}$ is occasionally observed with few $\mathrm{Ti}$ particles. This importantly suggests that the most of $\mathrm{Al}_{3} \mathrm{Ti}$ present in the melt microstructure does not directly originate from the pellet but are formed during the mechanical stirring stage in the melt. At higher melt temperatures of $1093 \mathrm{~K}$ and $1193 \mathrm{~K}\left(820^{\circ} \mathrm{C}\right.$ and $920^{\circ} \mathrm{C}$ ), however, Ti with sizes upto 370 and $490 \mu \mathrm{m}$, respectively, (Figure 11(b)) can be associated with the complete reaction of $\mathrm{Al}_{3} \mathrm{Ti}$, and thereby facilitates the successive reaction of $\mathrm{TiC}$. 


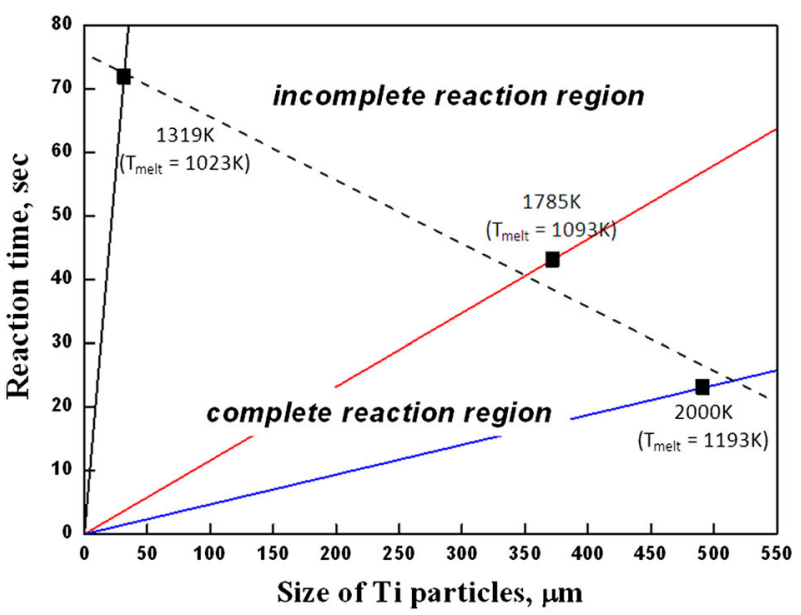

(a)

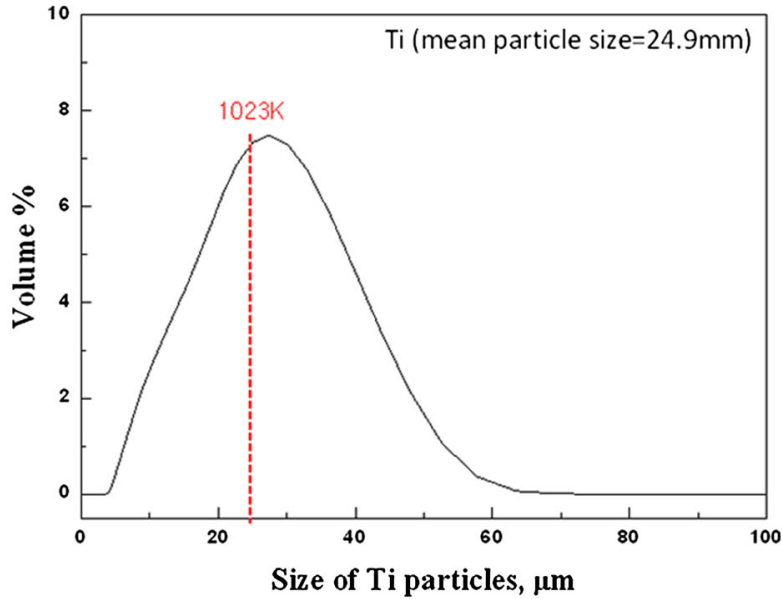

(b)

Fig. 11-(a) Reaction time calculated as a function of $\mathrm{Ti}$ particle size for different initial melt temperatures and (b) the size distribution of Ti powders used in the present work.

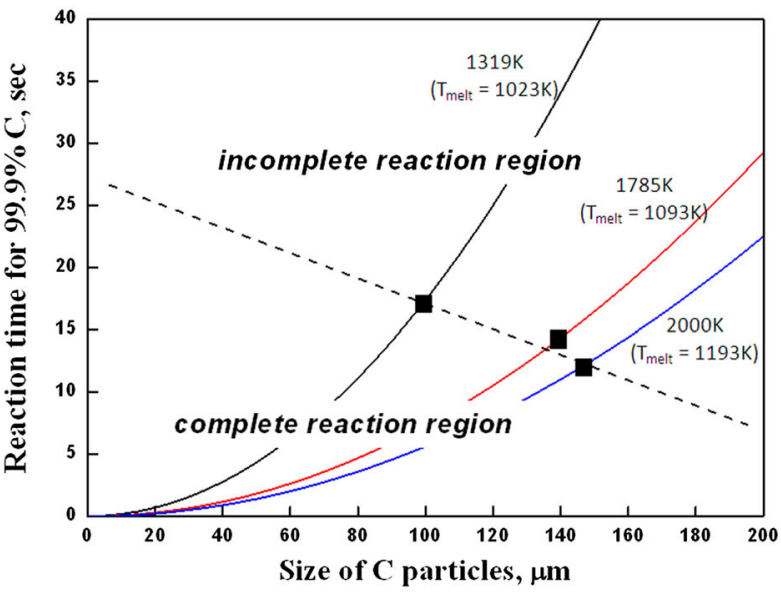

(a)

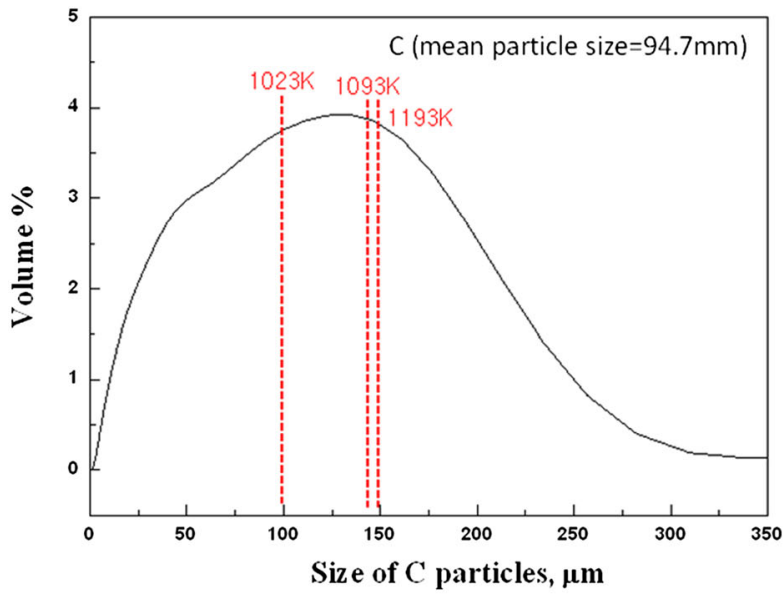

(b)

Fig. 12-(a) Reaction time calculated as a function of $\mathrm{C}$ particle size for different initial melt temperatures and $(b)$ the size distribution of $\mathrm{C}$ powders used in the present work.

\section{The kinetics of TiC formation}

The reaction kinetics of $\mathrm{TiC}$ formation has been calculated with an assumption that the reaction rate of TiC synthesis by Eq. [1] is much faster than that by Eq. [2] which involves the diffusion process. ${ }^{[39,40]}$ When employing small $\mathrm{Ti}$ and large $\mathrm{C}$ particles with mean particle sizes of 25 and $100 \mu \mathrm{m}$, respectively, in the present work, it is, therefore, suggested that the rate of the diffusion of $\mathrm{Ti}$ solutes in the $\mathrm{Al}$ matrix toward $\mathrm{C}$ is the controlling step of the TiC synthesis. Based on the stoichiometry of Eq. [2] and the spherical particle model, ${ }^{[39]}$ the molar diffusion rate of $\mathrm{Ti}$ across the intermediate reaction layer in the $\mathrm{Al}$ melt to the $\mathrm{C}$ surface can be equal to the carbon molar consumption rate, which can be defined as

$$
\frac{d V}{d t}=\frac{-\pi D\left(\frac{1+2 \beta}{\beta}\right)\left(\frac{6}{\pi}\right)^{1 / 3} \cdot N_{c}^{2 / 3} \cdot V^{4 / 3}}{N_{\mathrm{Al}} \cdot \frac{M_{\mathrm{Al}}}{\rho_{\mathrm{Al}}}+\frac{\rho_{c}}{M_{c}} \cdot \frac{M_{\mathrm{Ti}}}{\rho_{\mathrm{Ti}}} \cdot V}
$$

in units of $\left(\mathrm{m}^{3} / \mathrm{mol} \mathrm{s}\right)$. In Eq. [16], $\mathrm{V}=N_{c} \pi d p^{3} / 6$ is the total volume of $\mathrm{C}, D$ is the coefficient of Ti diffusion in Al, $N_{\mathrm{Al}}$ is the total moles of $\mathrm{Al}$ divided by the total number of $\mathrm{C}$ particles, $N_{c}$ in the initial powder mixture, and $\beta$ is the thickness of the reaction layer divided by the instantaneous diameter of the $\mathrm{C}$ particle, $d_{p}$.

The time for 99.9 pct of the molar volume consumption of the $\mathrm{C}$ particle during the TiC synthesis can be calculated from

$t=\left(\frac{10^{3}}{2} \cdot N_{\mathrm{Al}} \cdot \frac{M_{\mathrm{Al}}}{\rho_{\mathrm{Al}}} \cdot \frac{\rho_{c}}{M_{c}}+\frac{1}{6} \cdot \frac{\rho_{c}}{M_{c}} \cdot \frac{M_{\mathrm{Ti}}}{\rho_{\mathrm{Ti}}}\right) \cdot\left(\frac{\beta}{1+2 \beta}\right) \cdot \frac{d_{0}^{2}}{D}$

where $d_{0}$ is the initial particle size of $\mathrm{C}$ when $t=0$. In this study, $N_{\mathrm{Al}}=1.5 \mathrm{~mol}, \quad D=3.90 \times 10^{-7} \exp (-40.2 / R T)$ $\left(\mathrm{m} / \mathrm{s}^{2}\right)$, and $\beta=0.02$ were used. ${ }^{[40]}$ Figure $12(\mathrm{a})$ exhibits the calculated reaction time for 99.9 pct $\mathrm{C}$ consump- 

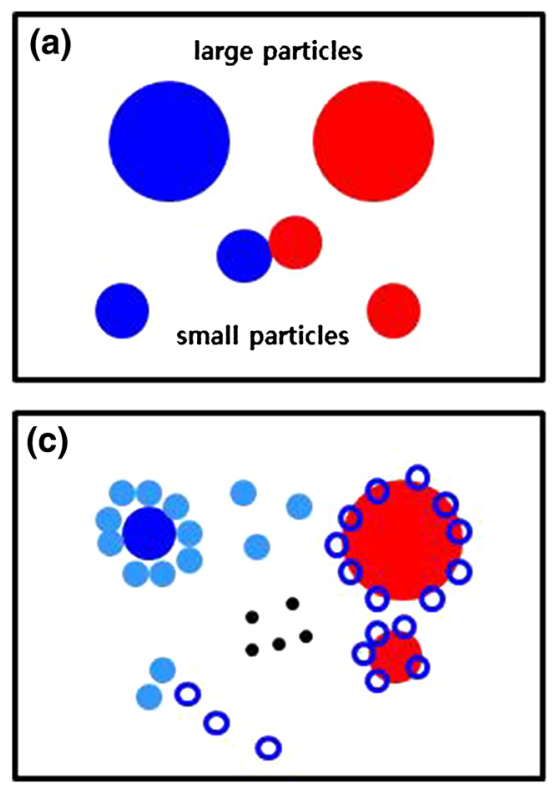

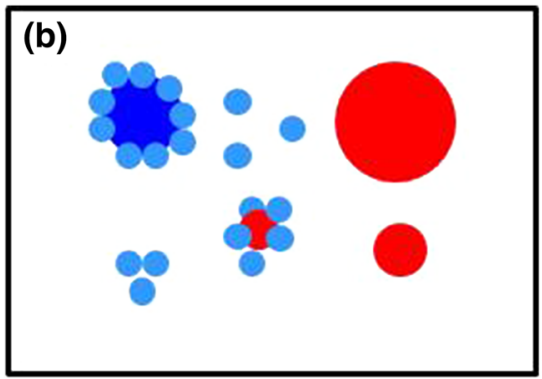

(d)

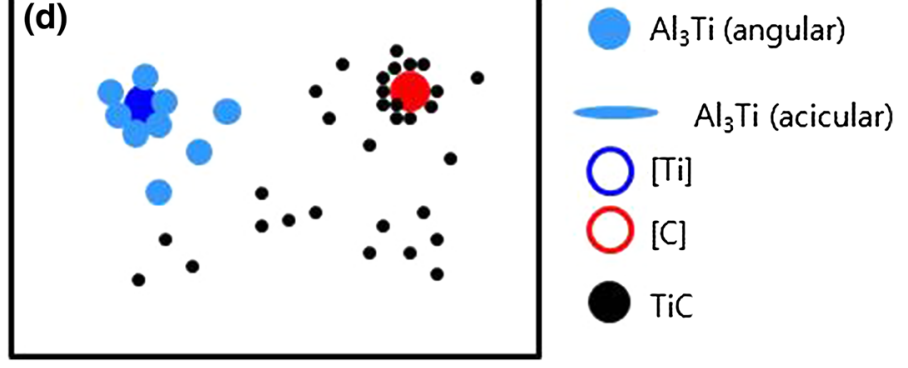

Fig. 13-A schematic illustration showing the reaction mechanism at a lower temperature condition.

tion as a function of $\mathrm{C}$ particle size along with the measured time, $\Delta t_{\mathrm{rxn}}$ for different initial melt temperatures. Considering that $\mathrm{C}$ particle can be completely converted into $\mathrm{TiC}$ during the reaction time of 17,14 , and $12 \mathrm{~s}$ by increasing the peak temperature to $1319 \mathrm{~K}$, $1785 \mathrm{~K}$, and $2000 \mathrm{~K}\left(1046^{\circ} \mathrm{C}, 1512^{\circ} \mathrm{C}\right.$, and $\left.1727^{\circ} \mathrm{C}\right)$, respectively (see Table $\mathrm{I}$ ), the maximum size of $\mathrm{C}$ particles at each initial temperature of the melt can be predicted as denoted in Figure 12(a). It is noted that C particles with sizes up to approximately $150 \mu \mathrm{m}$ are expected to react thoroughly as increasing the melt temperature up to $1193 \mathrm{~K}\left(920{ }^{\circ} \mathrm{C}\right)$. However, unreacted $\mathrm{C}$ particles that are often observed in the final microstructure is probably due the broad size distribution of the $\mathrm{C}$ powder used in this study as shown in Figure 12(b). Large $\mathrm{C}$ particles with sizes of over $150 \mu \mathrm{m}$ are, therefore, likely to remain unreacted even at a peak temperature of $2000 \mathrm{~K}\left(1727^{\circ} \mathrm{C}\right)$.

\section{Sequence of Microstructural Evolution}

Figures 13 and 14, respectively, illustrate the reaction mechanisms responsible for the in situ synthesis of $\mathrm{TiC}$ in the low and high temperature conditions (1023 K and $1093 \mathrm{~K}\left(750{ }^{\circ} \mathrm{C}\right.$ and $\left.820^{\circ} \mathrm{C}\right)$, respectively) employed in the present process. Firstly, if $\mathrm{Ti}$ and $\mathrm{C}$ particles with both large and small sizes are present in an Al melt at lower temperature (Figure 13(a)), Ti particles are surrounded with angular $\mathrm{Al}_{3} \mathrm{Ti}$ phases (Eqs. [6] and [7]) in the initial stage. A small $\mathrm{C}$ particle that is in direct contact with $\mathrm{Ti}$ is also surrounded with $\mathrm{Al}_{3} \mathrm{Ti}$ as shown in Figure 13(b) and then starts to react to form TiC by Eq. [4] (see Figure 13(c)). In this stage, $\mathrm{Al}_{3} \mathrm{Ti}$ phases are decomposed into [Ti] in the Al melt by Eq. [8], followed by diffusion of the solutes toward the surface of $\mathrm{C}$ particles. Finally the diffused [Ti] reacts with the solid $\mathrm{C}$ to form TiC by Eq. [2], while the large $\mathrm{C}$ is unlikely to be completely reacted and is rather surrounded with $\mathrm{TiC}$ aggregates as shown in Figure 13(d). In a similar way, the large $\mathrm{Ti}$ particle that remains incompletely reacted ends up being surrounded with angular $\mathrm{Al}_{3} \mathrm{Ti}$ phases (Figure 13(d)). This is in good agreement with the final microstructure obtained from the melt temperature of $1023 \mathrm{~K}\left(750^{\circ} \mathrm{C}\right)$ (see Figure $\left.15(\mathrm{a})\right)$. The reaction mechanism suggested for the lower temperature condition may also account for the microstructure evolution in the unreacted or reacting regions of a pellet or in a case of low $\mathrm{CuO}$ content (e.g., $0.03 \mathrm{~mol}$ in the present work).

Similarly to the lower temperature conditions, if there are $\mathrm{Ti}$ and $\mathrm{C}$ particles with both large and small sizes in the Al matrix (Figure 14(a)) at a high temperature condition of $1193 \mathrm{~K}\left(920^{\circ} \mathrm{C}\right)$, a large $\mathrm{Ti}$ particle is surrounded with angular $\mathrm{Al}_{3} \mathrm{Ti}$ phases, while a small Ti adjacent to $\mathrm{C}$ also forms $\mathrm{Al}_{3} \mathrm{Ti}$ phases that are likely to envelop the $\mathrm{C}$ particle as shown in Figure 14(b). Then the $\mathrm{C}$ particle surrounded with $\mathrm{Al}_{3} \mathrm{Ti}$ starts to react to form $\mathrm{TiC}$ by Eq. [4] and $\mathrm{Al}_{3} \mathrm{Ti}$ away from $\mathrm{C}$ sources are decomposed into [Ti] solutes in the Al melt by Eq. [8]. In such higher temperature conditions as a high initial melt temperature or high content of $\mathrm{CuO}$ addition (e.g., $0.2 \mathrm{~mol} \mathrm{CuO}$ in the present work), moreover, $\mathrm{C}$ particles are also likely to get dissolved into [C] in this stage (see Figure 14(c)) by Eq. [9] possibly due to a high temperature that exceeds $1554 \mathrm{~K}\left(1281^{\circ} \mathrm{C}\right)$ during the reaction. $\mathrm{Ti}$ and $\mathrm{C}$ with smaller initial sizes are now present as [Ti] and $[\mathrm{C}]$, respectively, which instantly drives them to synthesize $\mathrm{TiC}$ by Eq. [1]. In the meantime, [Ti] solutes are also likely to diffuse to a large $\mathrm{C}$ particle to form $\mathrm{TiC}$ by Eq. [2] and [C] solutes diffuse toward [Ti] decomposed from the $\mathrm{Al}_{3} \mathrm{Ti}$ particles to form $\mathrm{TiC}$ (Figures $14(\mathrm{~d})$ and (e)). In the final stage of the reaction as shown in Figure 14(f), along with a large volume fraction of $\mathrm{TiC}$, the large $\mathrm{C}$ particle that remains incompletely reacted is often surrounded by $\mathrm{TiC}$. This may interfere with further diffusion of [Ti] to the large $\mathrm{C}$ and hence leads to excess $\mathrm{Ti}$ localized in the $\mathrm{Al}$ melt, 

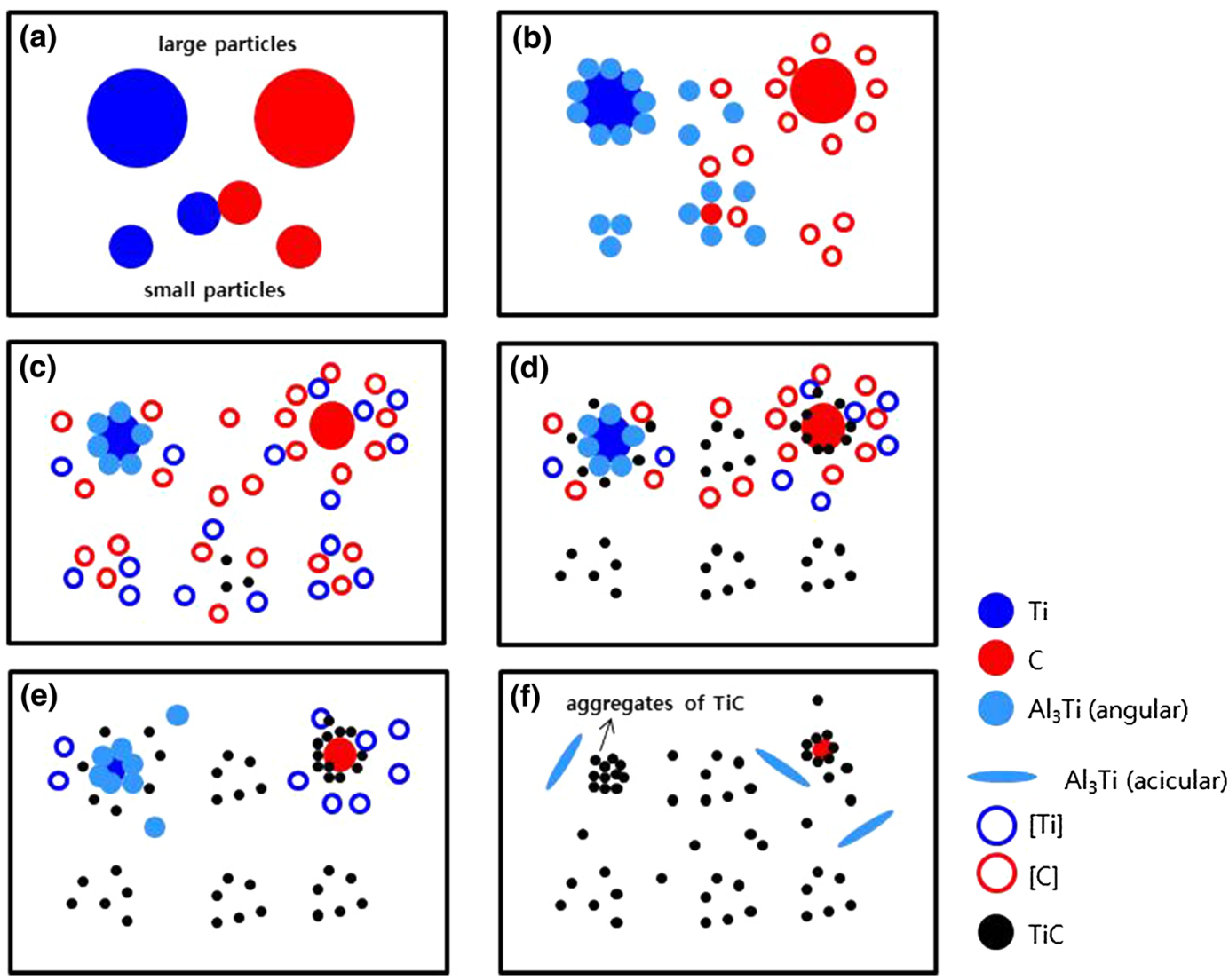

Fig. 14-A schematic illustration showing the reaction mechanism at a higher temperature condition.
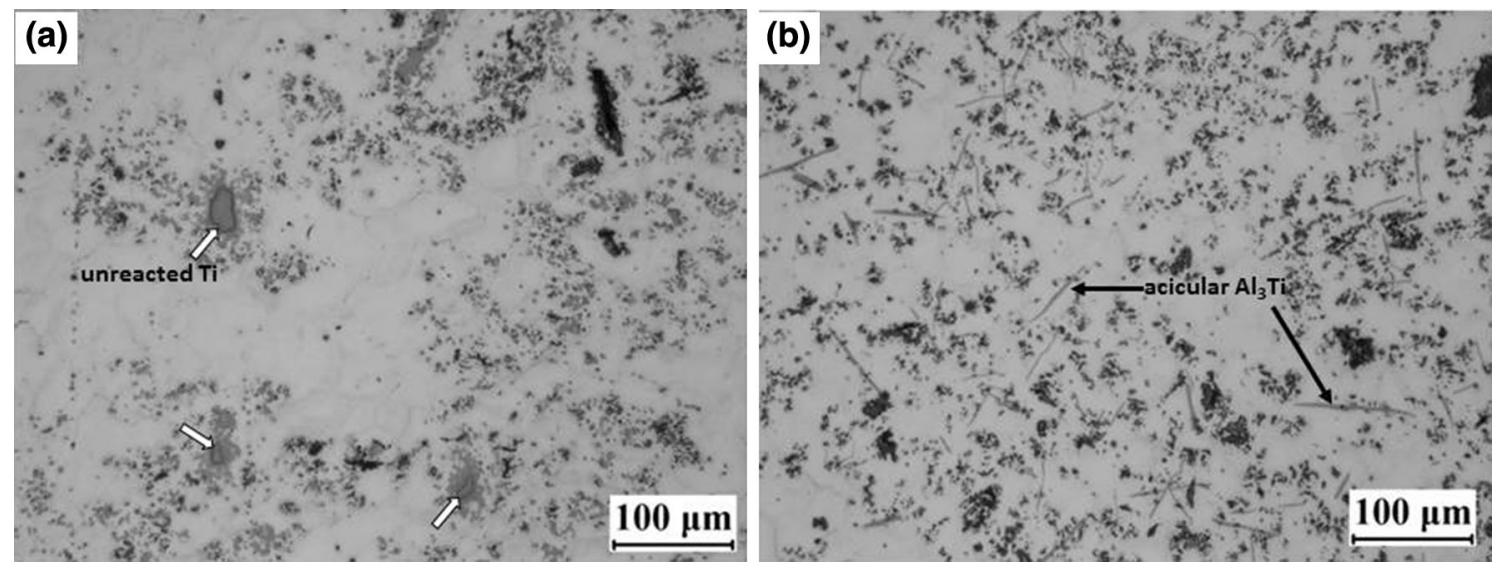

Fig. 15-Optical micrographs showing the final microstructure obtained from the melt temperature of $(a) 1023 \mathrm{~K}\left(750{ }^{\circ} \mathrm{C}\right)$ and $(b) 1193 \mathrm{~K}$ $\left(920{ }^{\circ} \mathrm{C}\right)$.

followed by the formation of acicular $\mathrm{Al}_{3} \mathrm{Ti}$ upon solidification. The large size $\mathrm{Ti}$, on the other hand, is thoroughly consumed to form $\mathrm{TiC}$ via $\mathrm{Eq}$. [8] followed by Eq. [1], but occasionally leaves $\mathrm{TiC}$ aggregates behind (Figure 14(f)). This well agrees with the final microstructure obtained from the initial melt temperature of $1193 \mathrm{~K}\left(920^{\circ} \mathrm{C}\right)$ as shown in Figure 13(b). Based on the suggested reaction mechanism, the microstructure control of $\mathrm{Al} / \mathrm{TiC}$ composites is now in progress and is to be further discussed in our future study that will present the mechanical properties for the enhanced performance.

\section{CONCLUSIONS}

$\mathrm{Al} / \mathrm{TiC}$ composites were fabricated by immersing a pellet of Al-Ti-C-CuO powder mixture into an $\mathrm{Al}$ melt at a temperature range of $1023 \mathrm{~K}$ to $1193 \mathrm{~K}\left(750{ }^{\circ} \mathrm{C}\right.$ to $920{ }^{\circ} \mathrm{C}$ ), followed by a self-sustaining combustion reac- 
tion. In situ-synthesized $\mathrm{TiC}$ particles with a size of approximately $1 \mu \mathrm{m}$ were well distributed in the final microstructure along with incomplete reaction products, such as carbon particles unreacted, polygonal-shaped $\mathrm{Al}_{3} \mathrm{Ti}$ phases and $\mathrm{TiC}$ agglomerates. The polygonalshaped $\mathrm{Al}_{3} \mathrm{Ti}$ phases mainly originated from the unreacted pellet layer that forms while the pellet is heated upto ignite and their volume fraction can be significantly reduced by accelerating SHS by increasing the initial melt temperature. Besides the melt temperature, the sizes of elemental powders are of importance and play a key role in controlling the microstructure of the in situ $\mathrm{Al} /$ $\mathrm{TiC}$ composites. Both $\mathrm{Ti}$ and $\mathrm{C}$ with large particle sizes are less likely to react completely to form $\mathrm{TiC}$ and are also associated with the formation of $\mathrm{TiC}$ aggregates even in the higher temperature condition provided in the developed process.

\section{ACKNOWLEDGMENTS}

The authors gratefully acknowledge a grant from the Fundamental R\&D Program for Core Technology of Materials funded by the Ministry of Knowledge Economy, Republic of Korea (project no. 10037308).

\section{REFERENCES}

1. X.C. Tong and H.S. Fang: Metall. Mater. Trans. A, 1998, vol. 29A, pp. 893-902.

2. P. Sahoo and M.J. Koczak: Mater. Sci. Eng., A, 1991, vol. A131, pp. 69-76.

3. I. Gotman, M.J. Koczak, and E. Shtessel: Mater. Sci. Eng., A, 1994, vol. A187, pp. 189-199.

4. H. Nakata, T. Choh, and N. Kanetake: J. Mater. Sci., 1995, vol. 30, pp. 1719-27.

5. Y.F. Liang, J.E. Zhou, and S.Q. Dong: Mater. Sci. Eng., A, 2010, vol. 527 , pp. $7955-60$.

6. X.C. Tong and A.K. Chosh: J. Mater. Sci., 2001, vol. 36 , pp. 4059-69.

7. T. Nukami and M.C. Flemings: Metall. Mater. Trans. A, 1995, vol. 26A, pp. $1877-84$.

8. M.K. Premkumar and M.G. Chu: Mater. Sci. Eng., A, 1995, vol. A202, pp. 172-78.

9. X.C. Tong: J. Mater. Sci., 1998, vol. 33, pp. 5365-74.

10. A.E.W. Jarfors, L. Svendsen, M. Wallinder, and H. Fredriksson: Metall. Trans. A, 1993, vol. 24A, pp. 2577-83.

11. B. Yang, G. Chen, and J. Zhang: Mater. Des., 2001, vol. 22, pp. $645-50$.
12. A.G. Merzhanov: J. Mater. Process. Technol., 1996, vol. 56, pp. $222-41$

13. P. Li, E.G. Kandalova, V.I. Nikitin, A.G. Makarenko, A.R. Luts, and Y. Zhang: Scripta Mater., 2003, vol. 49, pp. 699-703.

14. P. Li, E.G. Kandalova, and V.I. Nikitin: Mater. Lett., 2005, vol. 59, pp. 2545-48.

15. G.S. Vinod Kumar, B.S. Murty, and M. Chakraborty: J. Alloys Compd., 2005, vol. 396, pp. 143-50.

16. R. Bauri: Trans. Indian Inst. Met., 2009, vol. 62, pp. 391 95.

17. Y. Birol: J. Alloys Compd., 2008, vol. 454, pp. 110-17.

18. V.H. López and A.R. Kennedy: J. Colloid Interface Sci., 2006, vol. 298, pp. 356-62.

19. Y. Mazaheri, M. Meratian, R. Emadi, and A.R. Najarian: Mater. Sci. Eng., A, 2013, vol. 560, pp. 278-87.

20. Y.-H. Cho, J.-M. Lee, H.-J. Kim, J.-J. Kim, and S.-H. Kim: Met. Mater. Int., 2012, vol. 19, pp. 1109-16.

21. Y.-H. Cho, J.-M. Lee, H.-J. Kim, J.-J. Kim, and S.-H. Kim: Proc 13th Int Conf Alum Alloys, 2012. pp. 201-06.

22. W.-C. Lee and S.-L. Chung: J. Am. Ceram. Soc., 1997, vol. 80, pp. 53-61.

23. G. Xiao, Q. Fan, G. Meizhuan, and Z. Jin: Mater. Sci. Eng., A, 2006, vol. 425 , pp. $318-25$.

24. X.C. Tong and H.S. Fang: Metall. Mater. Trans. A, 1998, vol. 29A, pp. 875-91.

25. E. Zhang, S. Zeng, B. Yang, Q. Li, and M. Ma: Metall. Mater. Trans. A, 1999, vol. 30A, pp. 1147-51.

26. A.R. Kennedy, D.P. Weston, M.I. Jones, and C. Enel: Scripta Mater., 2000, vol. 42, pp. 1187-92.

27. H. Ding, X. Liu, Y. Lina, and G. Zhao: Scripta Mater., 2007, vol. 57, pp. 575-78.

28. Y. Choi and S.-W. Rhee: J. Am. Ceram. Soc., 1995, vol. 78, pp. $986-92$

29. Z. Wang, X. Liu, J. Zhang, and X. Bian: J. Mater. Sci. Lett., 2003, vol. 22, pp. 1427-29.

30. A. Contreras, C.A. Leon, R.A.L. Drew, and E. Bedolla: Scripta Mater., 2003, vol. 48, pp. 1625-30.

31. J. Zhang, J.-M. Lee, Y.-H. Cho, S.-H. Kim, and Y. Huashun: Scripta Mater., 2013, vol. 69, pp. 45-48.

32. M.S. Song, B. Huang, M.X. Zhang, and J.G. Li: Int. J. Refract. Met. Hard Mater., 2009, vol. 27, pp. 584-89.

33. R.A. Rapp and X. Zheng: Metall. Trans. A, 1991, vol. 22A, pp. 3071-75.

34. A. Banerji and W. Reif: Metall. Trans. A, 1986, vol. 17A, pp. 2127-37.

35. M.E. Fine and J.G. Conley: Metall. Trans. A, 1990, vol. 21A, pp. 2609-10.

36. A. Hibino and R. Watanabe: J. Jpn. Inst. Met., 1991, vol. 55, pp. $1256-62$

37. T. Matsubara, K. Uenishi, and K.F. Kobayashi: Mater. Trans., JIM, 2000, vol. 41, pp. 631-34.

38. J.-M. Lee, S.-B. Kang, T. Sato, H. Tezuka, and A. Kamio: Mater. Sci. Eng., A, 2003, vol. A343, pp. 199-209.

39. A.M. Kanury: Metall. Trans. A, 1992, vol. 23A, pp. 2349 56.

40. E. Zhang, S. Zeng, B. Yang, Q. Li, and M. Ma: Metall. Mater. Trans. A, 1999, vol. 30A, pp. 1153-57. 